\title{
Analysis of Hydrogen Sulphide and Carbon (IV) Oxide Corrosion in Oil Exploration and Exploitation Operations
}

\author{
*DOSUNMU, A; ECHENDU, K C \\ Departmen of Petroleum Engineering, University of Port llarcourt P.M.B. 5323, Nigeria
}

\begin{abstract}
This is an attempt to detcrmine the susceptibility of carbon IV oxide $\left(\mathrm{CO}_{2}\right)$ and Hydrogen Sulphide $\left(\mathrm{H}_{2} \mathrm{~S}\right)$ corrosion of three different materials, namely; Type (316) Austenite Stainless Stecl, Mild Steel and Conventional drill-pipe in sour environment $-\left(\mathrm{H}_{2} \mathrm{~S} /\right.$ mud medium and $\mathrm{CO}_{2} /$ mud medium). The weight loss and Coxperiment showed that mild steel material was the most susceptible material to corrosion in the environment while Type (316) Stainless Steel material exhibited the best performance of all the materials. The result of this study can be used in the design of crude/product flow lines in the refining and producing operations. (a.JASEM
\end{abstract}

The oil industry has for many years recorded significant losses arising from corrosion. Corrosion in oil wells has resulted in loss of production, reduction of efficiency, production contamination over design and reduced savings. $\mathrm{CO}_{2}$ gas dissolves in produced water or brine, to form carbonic acid, which lowers the $\mathrm{pH}$ of water. This makes it aggressive to carbon steel that forms the main constituent of production string and $\mathrm{Fe}_{2}\left(\mathrm{CO}_{3}\right)$ film is formed on the surface (Echendu, 1988).

$$
\begin{gathered}
\mathrm{CO}_{2} \text { gas dissolves in } \mathrm{H}_{2} \mathrm{O}(\mathrm{l}) \rightarrow \mathrm{H}_{2} \mathrm{CO}_{3}(\mathrm{aq}) \ldots \ldots \ldots \text { (1) } \\
\mathrm{Fe}_{2} \mathrm{O}_{3(\mathrm{~g})}+3 \mathrm{H}_{2} \mathrm{CO}_{3(\mathrm{~m})} \rightarrow \mathrm{Fe}_{2}\left(\mathrm{CO}_{3}\right)_{3(\mathrm{~m})}+3 \mathrm{H}_{2} \mathrm{O}_{\mathrm{(g}} \ldots \ldots \text { (2) }
\end{gathered}
$$

Similarly, dissolved $\mathrm{H}_{2} \mathrm{~S}$ causes pitting, corrosion of production string, and defects in the black iron sulphide film formed initially by general corrosion as shown below.

$$
\mathrm{Fe}_{(\mathrm{s})}+\mathrm{H}_{2} \mathrm{~S}_{(\mathrm{g})} \rightarrow \mathrm{FeS}_{(\mathrm{s})}+\mathrm{H}_{2(\mathrm{~g})} \ldots \ldots \text { (3) }
$$

Thus, the concentrations of $\mathrm{CO}_{2}$ and $\mathrm{H}_{2} \mathrm{~S}$ gases in an oil formation are critical in choosing the type of down-hole equipment during drilling and completion operations. This study aims at comparing the susceptibility of Type (316) Stainless Steel, Mild Steel and Conventional drill-pipe materials at different $\mathrm{H}_{2} \mathrm{~S}$ and $\mathrm{CO}_{2}$ concentrations using weight loss method. Also considered, is the corrosion rate as a function of time at different concentrations of $\mathrm{CO}_{2}$ and $\mathrm{H}_{2} \mathrm{~S}$ in drilling mud. Corrosion is a major problem in the drilling, production, refining and transportation sector of the oil industry. Several authors have investigated different aspects of this subject. Some of these include Stanford (1984) who studied corrosion in production strings and concluded that combinations of chemical and mechanical problems were responsible for corrosion. Farshad and Bradhum (1983) evaluated the problem of corrosion and designed a completion and corrosion mitigation program that will afford the maximum rate of return on the investment made. Also Dosunmu and Alaka (1992) highlighted the use of corrosion inhibitors in the mitigation of corrosion in the oil industry.

\section{MATERIALS AND METHODS}

\section{$\mathrm{Mud} / \mathrm{H}_{2} \mathrm{~S}$ Mixture Preparation}

Kipps apparatus is used for the experimental set up as. Iron II sulphide sticks are put in the apparatus and $\mathrm{HCl}$ acid is introduced. Enough acid is introduced so that it will enter the second chamber and the reaction starts. The tap is opened and $\mathrm{H}_{2} \mathrm{~S}$ gas produced is bubbled into the drilling mud solution through the delivery tube. Interval of 60 seconds, 150 seconds and 240 seconds bubbling times are used for the experiment.

\section{Mud/CO $\mathrm{O}_{2}$ Mixture Preparation}

A similar apparatus is used for this preparation. Calcium Carbonate is kept in place of the Iron II Sulphide. Same procedure and bubbling times are used as reported above.

\section{Preparation of Corrosion Coupons}

The following Coupons were used; Austenite Stainless

\footnotetext{
*Corresponding author
} 
Fig. 1: Bubbling Time vs Weight Loss of Austenite Stainless Steel (type 316) in H2S/Mud Environment

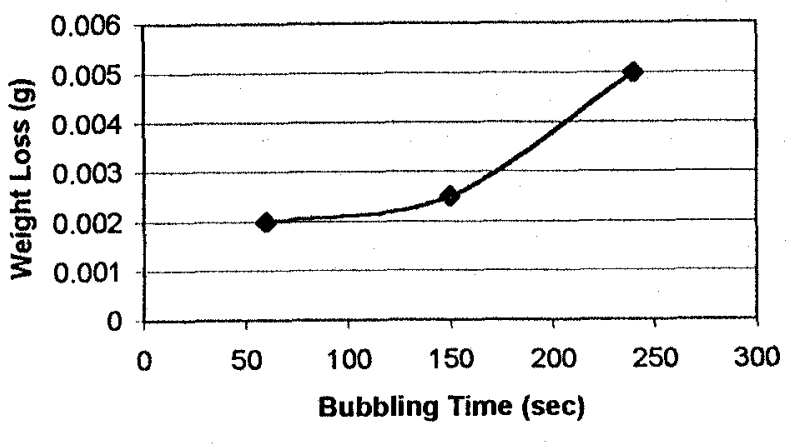

Fig. 2: Bubbling Time vs Weight Loss of Austenite Stainless Steel (Type 316) in CO2/Mud Environment

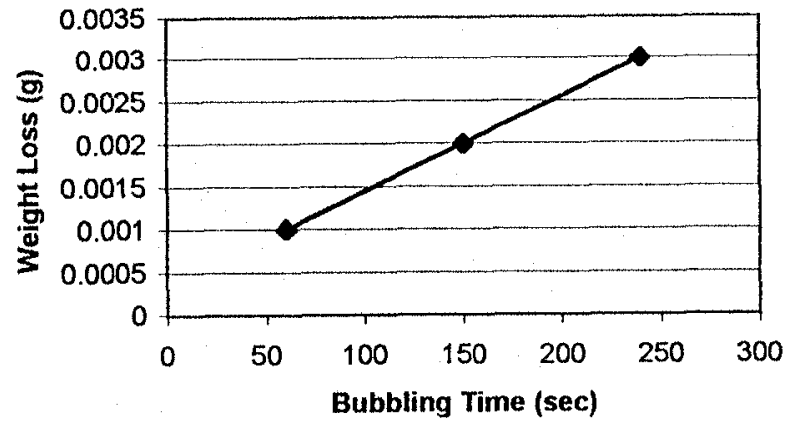

Fig. 3: Bubbling Time vs Weight Loss of Mild Steel Drill Pipe in H2S/Mud Environment

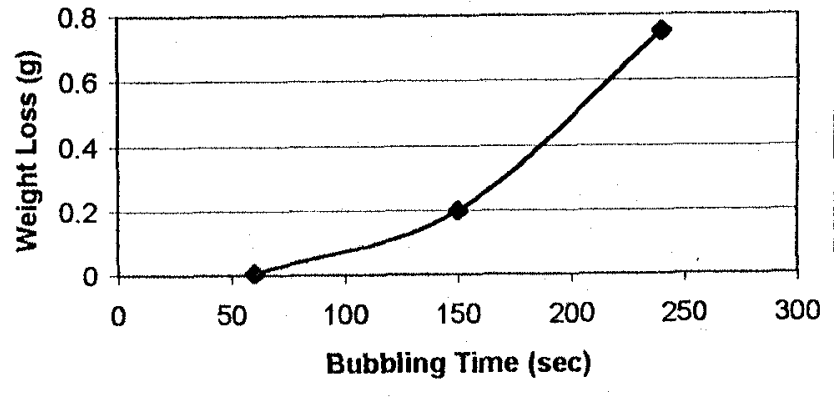




\section{Analysis of Hydrogen Sulphide and Carbon (IV) Oxide Corrosion}

(ii) Conventional Drill Pipe Coupon

Six Coupons, each of the three materials was cut. The Coupons were cut to size $1 " \times 1$ " heterogeneous thickness. Hole of $2.5 \mathrm{~mm}$ in diameter was bored at one end of each Coupon. The Coupons were then individually fastened using ropes through the bored holes. The surface of each of the Corrosion Coupons was first mechanically cleaned with sand-paper and then immersed individually into a $200 \mathrm{ml}$ of pickling solution for $5-6$ minules at room temperature of $29 \pm 0.05^{\prime \prime} \mathrm{C}$. This is then followed by rinsing with distilled water and left to dry in air under fan for $10-$ 15 minutes and then weighed and stored in a dessicator prior to the corrosion test

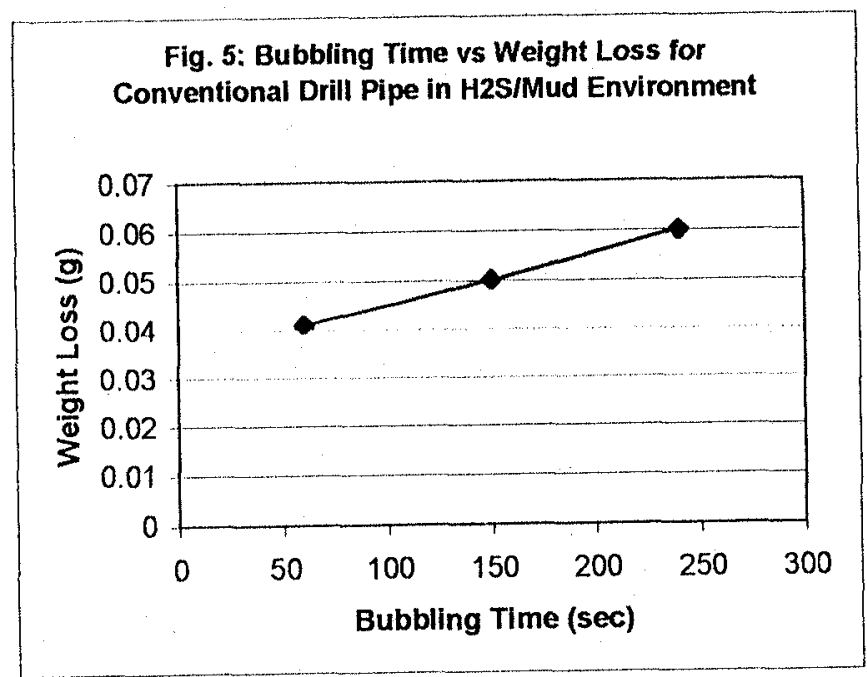

Corrosion Test for Drilling Mud $\left(\mathrm{H}_{2} \mathrm{~S}\right)$

Three corrosion coupons of Austenite - Type 310 stainless steel, three coupons of mild steel (Mactesite - Type 410) and three coupons of conventional drill pipe were immersed in three beakers containing varying quantities of $\mathrm{H}_{2} \mathrm{~S}$ gas. The immersion period varied from 3 days to 2 weeks. At the end of each period, coupons were rinsed in distilled water and dipped in pickling solution for $10-15$ minutes. It was then removed, flushed with distilled water again and dried in an oven for 3 minutes and reweighed.
Corrosion Test for Drilling Mud $\left(\mathrm{CO}_{2}\right)$

The same procedure is followed for the drilling mud containing $\mathrm{CO}_{2}$ as in the case of $\mathrm{H}_{2} \mathrm{~S}$ using the remaining three coupons of each material.

They were immersed in the beakers, as was done in the $\mathrm{H}_{2} \mathrm{~S}$ /mud mixture test. The immersion periods also vary from 3 days to 2 weeks. At the end of each period, the coupons were rinsed in distilled water and dipped in pickling solution for $10-15$ minutes, then removed and flushed with distilled water again and dried in an oven for 3 minutes and reweighed.

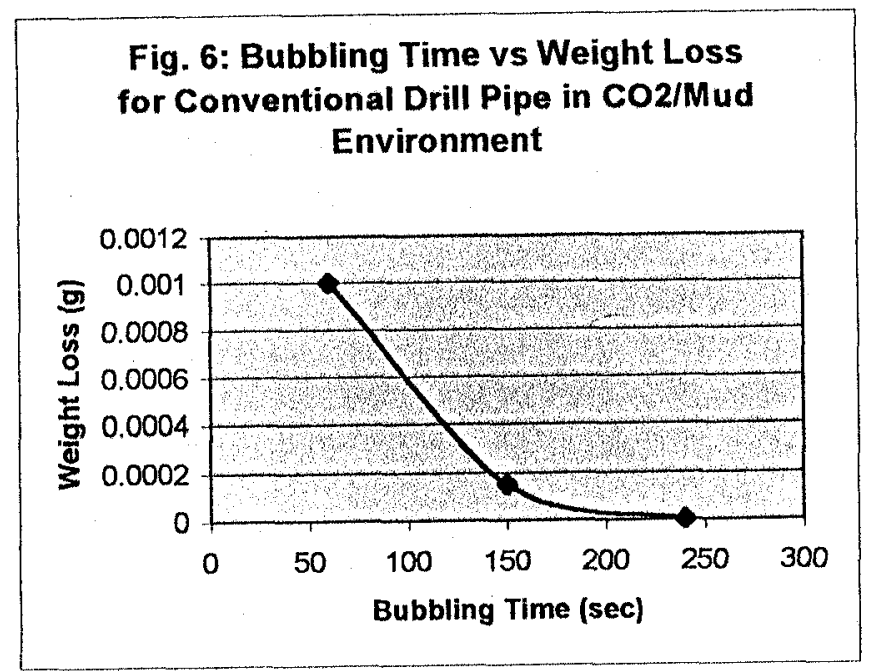




\section{RESULTS AND DISCUSSIONS}

Results of weight loss with time of Austenite stainless steel (type 316) drill pipe coupon immersed in $\mathrm{H}_{2} \mathrm{~S} / \mathrm{CO}_{2}$ environments at room temperature of 29 $\pm 0.05^{\circ} \mathrm{C}$ is presented in Figures 1 and 2 above. Results of weight loss with time of mild steel drill pipe coupon immersed in $\mathrm{H}_{2} \mathrm{~S} / \mathrm{CO}_{2}$ gas at room temperature of $29 \pm 0.05^{\circ} \mathrm{C}$ are as shown in Figures 3 and 4. Results of weight loss with time of conventional drill pipe coupon immersed in $\mathrm{H}_{2} \mathrm{~S} / \mathrm{CO}_{2}$ gas at room temperature of $29 \pm 0.05^{\circ} \mathrm{C}$ are shown in Figures 5 and 6 . Figures 1 to 6 show the trends of weight loss versus bubbling times for the three materials in the two mediums. The progressive trend of weight loss with time in each medium shows that corrosion rate generally increases with time. Figure 1 reveals that as the concentration of $\mathrm{H}_{2} \mathrm{~S}$ gas in the drilling mud increases, the more susceptible Austenite Stainless steel (Type 316) is to corrosion. For $\mathrm{CO}_{2} /$ mud medium, as the quantity of $\mathrm{CO}_{2}$ gas dissolved increases, susceptibility of Austenite Stainless steel (Type316) to corrosion also increases. This is shown in Figure 2. However the weight loss of this material is low. In $\mathrm{H}_{2} \mathrm{~S} /$ mud medium, mild steel corrosion rate increases as the quantity of dissolved $\mathrm{H}_{2} \mathrm{~S}$ gas increases. In $\mathrm{CO}_{2}$ /mud medium mild steel yielded to corrosion with low quantity of dissolved $\mathrm{CO}_{2}$ gas. These are evident from Figures 3 and 4. From Figures 5 and 6 , it can be seen that the conventional drill pipe is the most affected by corrosion in $\mathrm{H}_{2} \mathrm{~S} /$ mud medium. In $\mathrm{CO}_{2}$ /mud medium, this material showed excellent performance. The least weight loss was observed from this material.

Conclusion: The conventional drill pipe is the most affected by corrosion in $\mathrm{H}_{2} \mathrm{~S} /$ mud medium. It exhibits higher weight losses in the medium. In $\mathrm{CO}_{2} /$ mud medium, this material showed excellent performance. There was no observable corrosion or weight loss in this material in the $\mathrm{CO}_{2}$ /mud medium. The mild steel material showed the highest susceptibility to corrosion out of the three materials. Stainless Steel (Type 316) is in general the most suitable material for use pipes as it shows a moderate rate of corrosion in both mediums. However, the conventional drill pipe is recommended for use since in Niger Delta the crude generally contains insignificant amounts of $\mathrm{H}_{2} \mathrm{~S}$.

\section{REFERENCES}

Dosunmu, A.and Alaka, C.O -Development of the Corrosion Inhibitors for Oil field corrosion froth local raw material, 1992.

Echendu, K.E -Corrosion Rates of Hydrogen Sulphide and Carbon IV Oxide in Oil Wells, B. Eng Project, University of Port Harcourt, 1988 .

Farshad, F.F and Garber, J.D. -How to increase gas well production and temper corrosion; Part3Petroleum Engineering International, June 1993

Stanford, A. Failure Analysis Isolates production problem Petroleum Engineering International, June 1984 